\title{
Cytochemical and immunocytochemical ultrastructural study of nucleoproteins during nucleologenesis in 8-cell bovine embryos
}

\author{
L Antalíková 1 , J Rozinek ${ }^{1}$, J Fulka Jr 1,2* , I Goll 1 \\ with the technical assistance of M Horská \\ ${ }^{\dagger}$ Research Institute of Animal Production, Prague 10-Uhrínéves, Czech Republic; \\ 2 Institute of Animal Physiology and Genetic Research, Babraham Hall, Cambridge, UK
}

(5th Franco-Czechoslovak Meeting, Jouy-en-Josas, December 1992)

\begin{abstract}
Summary - The aim of this study was to characterize embryonic nucleologenesis by determining the appearance and localization of acid argyrophilic, basic lysine-rich and histone proteins in 8-cell bovine embryos. Two silver staining techniques, ethanolic phosphotungstic acid (PTA) and immunocytochemical methods using specific antibodies, were applied at the ultrastructural level. The silverstained proteins were detected at the onset of nucleologenesis on the periphery of the dense nucleolus precursor bodies (NPBs). The amounts of these proteins increased during the transformation of the NPBs into the fibrillogranular nucleolus. At this stage the well-developed dense fibrillar components encircling fibrillar centres showed intense staining. PTA-positive (basic lysine-rich) proteins were present within most nucleolar structures during nucleologenesis as well as in the chromatin. Histones $\mathrm{H} 2 \mathrm{~B}, \mathrm{H} 3$ and $\mathrm{H} 4$ were concentrated throughout the chromatin including the nucleolusassociated chromatin. At the onset of nucleologenesis, histones were absent in the NPBs. The first weak histone labelling was detected in the multivacuolated NPBs, both in the fibrous mass as well as inside the vacuoles. Nucleolar histones appeared with the massive penetration of DNA into the NPBs. We suggest that nucleologenesis may serve as a criterion of normal early embryonic development and that the proteins involved in the process of nucleologenesis and transcription could be used as chemical markers of nucleolar function.
\end{abstract}

nucleolus / nucleoprotein / cattle / embryo

Résumé - Étude cytochimique et immunocytochimique ultrastructurale de nucléoprotéines pendant la nucléologenèse dans l'embryon bovin de 8 cellules. L'objet de cette étude est d'analyser la nucléologenèse en déterminant l'apparition et la localisation de protéines acides argyrophiles, basiques, riches en lysine et d'histones dans les embryons bovins de 8 cellules. Des techniques à l'argent, à l'acide phosphotungstique (PTA) éthanolique et 2 techniques immunocytochimiques ont été appliquées en microscopie électronique. Les protéines argyrophiles ont été détectées au début de la nucléologenèse à la périphérie des corps précurseurs de nucléole (NPB). La quantité de ces protéines augmente pendant la transformation du NPB en nucléole fibrogranulaire. $\dot{A}$ ce stade le composant fibrillaire dense bien développé entourant les centres fibrillaires montre une coloration intense. Des protéines basiques riches en lysine (PTA+) sont présentes dans la plupart des composants nucléolaires pendant la nucléologenèse et dans la chromatine. Les his-

\footnotetext{
* Correspondence and reprints
} 
tones $\mathrm{H} 2 \mathrm{~B}, \mathrm{H} 3$ et $\mathrm{H} 4$ sont concentrées dans la chromatine, y compris la chromatine associée au nucléole. Au début de la nucléogenèse, les histones sont absentes des NPBs. Le premier marquage faible est détectable dans les NPBs en cours de vacuolisation, dans la masse compacte et dans les valuoles (agrégats). Les histones nucléolaires accompagnent la pénétration massive d'ADN dans le NPB. Nous suggérons que la morphogenèse nucléolaire soit utilisée comme un critère du développement embryonnaire normal et que les protéines impliquées dans la nucléologenèse et la transcription soient utilisées comme marqueurs de la fonction nucléolaire.

nucléole / nucléoprotéine / espèce bovine / embryon

\section{INTRODUCTION}

Nucleoli are nuclear structures reflecting the state of activity and differentiation of each cell. They are the morphological expression of a complex machinery in which repetitive genes of rDNA are transcribed into rRNA, the latter being processed and packed into the ribosomal subunit.

During early mammalian embryonic development, functional nucleoli are absent. They develop gradually via the process of nucleologenesis linking morphological events with the onset of functional activity. This process of embryonic nucleologenesis has been described in a few domestic ruminants (Chartrain et al, 1987; King et al, 1988, 1989).

In cow embryos, the whole nucleologenesis process takes place at the 8-cell stage (Camous et al, 1986; Kopecný et al, 1989a). The authors have divided this process into 4 clear-cut stages: stage 1 (S1) - after fertilization, nucleolar precursor bodies (NPBs) are present as small, round-shaped structures, composed of a compact homogeneous mass of fibrils; stage 2 (S2) - a large central nucleoplasm-like vacuole develops in the NPBs; stage 3 (S3) - nucleolar differentiation proceeds with the formation of numerous small secondary vacuoles. Dense NPBs as well as vacuolated NPBs are in close association with perinucleolar chromatin; stage 4 (S4) - typical fibrillogranular nu- cleoli contain fibrillar centers surrounded by dense fibrillar components and increasing amounts of granular component which becomes apparent.

It is now accepted that the 8-cell stage of early embryonic development in the cow is an important period during which nucleolar transformation takes place and the onset of transcriptional activity is detected for the first time (Kopečný et al, 1989a; Telford et al, 1990). We therefore concentrated our attention on this developmental stage.

The aim of the present study was to analyze the localization of: 1) acidic argyrophilic proteins; 2) basic lysine-rich proteins; and 3) histones, which are in direct relation to the nucleolar structures and are thought to play an important regulatory function in the process of transcription. By correlating the distribution and quantity of 3 types of nucleoproteins in nucleoli undergoing differentiation we hope to improve our knowledge of the relationship between these proteins and of their physiological role in nucleolar activity.

\section{MATERIAL AND METHODS}

The 8-cell bovine embryos $(n=17)$ originated from superovulated heifers. The animal were killed 3-4 d after the onset of oestrus. The embryos were flushed from the oviducts and carefully evaluated. Only those embryos showing perfect morphology were used for further experi- 
ments. They were briefly precultured for $1-2 \mathrm{~h}$ in $0.1 \mathrm{ml}$ culture medium (TC 199) as droplets under paraffin oil at $37.5^{\circ} \mathrm{C}$ in an atmosphere of $5 \% \mathrm{CO}_{2}$ in air (Fulka $\mathrm{Jr}$ et al, 1986). After this time interval, embryos were re-evaluated, washed briefly in PBS without protein and used for the following procedures.

\section{Silver staining applied in toto before embedding in Epon 812}

After brief glutaraldehyde fixation $(2.5 \%$ for 30 min at $4^{\circ} \mathrm{C}$ ), embryos were postfixed in Carnoy's solution (methanol / glacial acetic acid, 3:I, for $20 \mathrm{~min}$ at room temperature) and carefully washed in distilled water. Silver staining procedure (Likovsky and Smetana, 1981), using a mixture $100 \% \mathrm{AgNO}_{3}$ and formaldehyde developer $1: 1$ for $6-8 \mathrm{~min}$ at $60^{\circ} \mathrm{C}$ was applied. After repeated brief washing in distilled water, the samples were dehydrated in ethanol and embedded in Epon 812. One set of sections were stained with uranyl acetate and lead citrate, while the second set served as unstained controls.

\section{Staining with ethanolic solution of phosphotungstic acid (PTA) before embedding in Epon 812}

After glutaraldehyde fixation $\left(2.5 \%, 2 \mathrm{~h}, 4^{\circ} \mathrm{C}\right)$, the embryos were dehydrated with an ethanol series and incubated for $16-18 \mathrm{~h}$ at $4^{\circ} \mathrm{C}$ in $3 \%$ PTA in absolute ethanol according to Sheridan and Barrnett (1969). Samples were then washed in absolute ethanol and embedded in Epon 812. Grids with ultrathin sections were washed, dried and observed without further contrast.

\section{Embedding in the hydrophilic resin LowicryI K4M}

The procedure was performed according to the method described by Altman et al (1984). After glutaraldehyde fixation and brief washing, samples were dehydrated in a series of ethanol, infiltered in Lowicryl and polymerized by indirect ul- traviolet irradiation. Ultrathin sections were mounted directly on gold grids and processed for the following step.

\section{Silver staining with a 1-step method according to Howell and Black (1980)}

Grids with sections were floated for $10 \mathrm{~min}$ at room temperature in Carnoy's solution and after washing, a mixture containing 2 vol $50 \% \mathrm{AgNO}_{3}$ and 1 vol $1 \%$ gelatin in $1 \%$ formic acid was applied for $10 \mathrm{~min}$ at room temperature. After washing and drying, the sections were not poststained.

\section{Immunocytochemical demonstration of histones}

\section{Reagents}

Rabbit specific anti-histone sera which had been previously tested, H2B (Müller et al, 1985), H3 (Müller et al, 1982) and $\mathrm{H} 4$ (Müller et al, 1987), were used. The anti-rabbit IgG antibodies were: goat anti-rabbit IgG conjugated peroxidase; donkey biotinylated anti-rabbit IgG; and $15 \mathrm{~nm}$ colloidal gold streptavidin-coated particles (Amersham). Buffer A was composed of PBS pH 7.2, $0.01 \%$ Tween, and $10 \%$ decomplemented goat serum. Buffer $B$ for washing was composed of PBS pH 7.2 and $0.01 \%$ Tween.

\section{Peroxidase method}

Ultrathin Lowicryl sections preincubated in buffer $\mathrm{A}$ for $20 \mathrm{~min}$ at $20^{\circ} \mathrm{C}$ were treated for $16 \mathrm{~h}$ at $4^{\circ} \mathrm{C}$ with specific antisera diluted $1: 500$ in the same buffer. Following extensive washing in buffer $B$, they were incubated for $1 \mathrm{~h}$ at $20^{\circ} \mathrm{C}$ in 1:50 goat anti-rabbit IgG coupled to horseradish peroxidase in buffer A. After several washes in PBS, the peroxidase was revealed by $3 \mathrm{~min}$ incubation in $22 \mathrm{mg}$ diaminobenzidine $+175 \mathrm{ml}$ PBS $+3 \mu \mathrm{l} 5 \% \mathrm{H}_{2} \mathrm{O}_{2}$ followed by extensive washing in PBS and distilled water and drying of the sections. The final peroxidasediaminobenzidine product was osmicated for 45 min at $60^{\circ} \mathrm{C}$ in $\mathrm{OsO}_{4}$ vapor.

\section{Colloidal gold method}

The pre-incubation, washing and incubation with specific antisera were similar to the peroxidase 
method. The second antibody was anti-rabbit IgG coupled to biotin diluted 1:50 in buffer A. After $1 \mathrm{~h}$ at $20^{\circ} \mathrm{C}$, it was washed carefully in buffer $B$. The sections were finally incubated for 30 min at $20^{\circ} \mathrm{C}$ in 1:50 colloidal gold-streptavidin in PBS, and washed extensively in PBS and distilled water.

For both methods, the negative controis were carried out. The possible nonspecific absorption of either the antibody or the contrasting agents were tested by replacement of the first antiserum by normal rabbit serum, and or by replacement of one of the steps of the technique by PBS incubation.

Ultrathin sections were prepared on an Ultratome III LKB Nova ultramicrotome and examined under a JEOL $100 \mathrm{CX}$ II electron microscope at $80 \mathrm{kV}$.

\section{RESULTS}

Four main stages of nucleologenesis in the early cow embryo were observed according to the ultrastructural morphology described by Kopečný et al (1989a).

S1: this is characterized by the presence of rounded NPBs, which persist up to the beginning of the 8-cell stage.
S2: a large central lucid area develops in the NPB. According to the recent nucleolar terminology, this entity will be termed the NPB-vacuole.

S3: the primary vacuole loses its sharply delineated boudary, and a clump of chromatin appears within it. A continuity with perinucleolar chromatin is visible. Around the secondary vacuoles, the dense fibrillar component can be distinguished as well as the first granular component.

S4: typical nucleolonemal structure appears as well as small fibrillar centers.

\section{Silver staining}

Localization of acidic argyrophilic proteins was detected in dense NPB of stage 1 within a convex-shaped area (lenticle) at the NPB periphery (fig 1).

During stage 2 silver grains were present in the peripheral filamentous area around the central vacuole (fig 2). The inside of the central vacuole was devoid of silver.

Stage 3 involved the formation of small secondary vacuoles which remained free

Fig 1. Silver staining; pre-embedding silver staining, sectons were contrasted; NPB with the lenticle containing silver positive material (arrow); × 80000 .

Fig 2. Silver staining; post-embedding silver staining on Lowicryl section without any further contrast; NPB with central vacuole (CV): the peripheral part of the fibrous material contains the fine silver grains; $x 42000$.

Fig 3. Silver staining; Pre-embedding silver staining, sections were contrasted; NPB with secondary vacuoles (SV); dense fibrillar component surrounding vacuoles is impregnated with silver; $x 76000$.

Fig 4. Silver staining; post-embedding silver staining on Lowicryl section without any further contrast; part of fibrillogranular nucleolus; silver granules are accumulated within the dense fibrillar component and in a small fibrillar center (arrow); $\times 44000$.

Fig 5. PTA staining; dense nucleolus precursor body $(\mathrm{npb})$ and the masses of chromatin (ch) are intensely stained; $x 39000$.

Fig 6. PTA staining; NPB with a central vacuole which is filled with many clumps of PTA-positive material (arrow); NPB wall and nucleolus-associated chromatin (ch) are also stained; $x 65$ 000; PTApositive clusters including the inner vacuolar surface; $x 65000$.

Fig 7. PTA staining; multivacuolated NPB with PTA-positive material inside secondary vacuoles; $x 62000$.

Fig 8. PTA staining; fibrillogranular nucleolus; strongly stained dense fibrillar component and fibrillar centers; gc: granular component; x 60000 . 
of silver. Irregular silver deposits were seen in the dense fibrillar component surrounding the vacuoles (fig 3 ).

At the end of the 8-cell stage (stage 4), numerous silver grains were deposited on the dense fibrillar component while fibrillar centers appeared to be less stained (fig 4). The granular component was devoid of silver staining.

\section{PTA staining}

Basic lysine-rich proteins identified using ethanolic PTA were present in high quantities within the $S 1$ compact rounded NPB (fig 5). Clumps of condensed chromatin closely associated with NPB (nucleolusassociated chromatin) also displayed strong PTA staining (fig 5).

At the following stage of nucleologenesis (S2), NPBs were characterized by a large central vacuole containing many PTA-staining patches. Similar patches were arranged on the inner vacuolar surface (fig 6, 6a).

Multivacuolated NPBs (S3) showed secondary vacuoles filled with clumps of PTA-positive material (fig 7). In several areas increased staining was visible, especially around and amongst the vacuoles.

During the last step (S4) small fibrillar centers could also be recognized. All nucleolar components were PTA-positive with a different intensity of staining. The dense fibrillar component surrounding the fibrillar centers as well as the fibrillar centers themselves showed a very strong reaction, while the granular component was stained to a lesser degree (fig 8).

\section{Demonstration of histones}

The staining patterns of histones $\mathrm{H} 2 \mathrm{~B}, \mathrm{H} 3$ and $\mathrm{H} 4$ obtained in the present study largely coincide with chromatin distribution within the nucleus. The labelling was located over the nucleolus-associated chromatin (figs 9-12). At the beginning of nucleologenesis (S1), the compact NPB was without any labelling as well as those NPBs containing a large central vacuole (fig 2). A weak labelling of histones was first detected within the multivacuolated nucleoli (S3) in various localization: 1) in transition areas between nucleolusassociated chromatin and the nucleolus itself (fig 9); 2) within NPB = filamentous material (fig 11); and 3) inside the secondary vacuoles (fig 12).

\section{DISCUSSION}

In this report we extend our previous observations which described silver-stained nuclear proteins in preimplantation cow embryos (Anlalíková and Fulka Jr, 1990). Silver staining techniques adapted for electron microscopy have enabled us to local-

Fig 9. Immunocytochemical demonstration of histone; histone $\mathrm{H} 3$, transitional area between labelled nucleolus-associated chromatin (ch) and multivacuolated NPB; weak labelling at the periphery of NPB (small arrowheads); $\times 30000$.

Fig 10. Immunocytochemical demonstration of histone, histone $\mathrm{H} 4$; weak labelling of nucleolusassociated chromatin (ch); $\times 30000$.

Fig 11. Immunocytochemical demonstration of histone; histone $\mathrm{H} 2 \mathrm{~B}$; weak labelling within the chromatin and in the fibrous wall of vacuolated NPB (arrowheads); $x 30000$.

Fig 12. Immunocytochemical demonstration of histone; histone $\mathrm{H} 3$; labelling of histones in chromatin and in the peripheral part of NPB (arrow heads) as well as inside the secondary vacuole (arrow); $\times 40000$. 
ize metal deposits associated mainly with the dense fibrillar components. These deposits were therefore thought to indicate the acquisition of rDNA transcriptional activity (Fakan and Hernandez-Verdun, 1986). Based on autoradiographic data (Kopecný, 1989), it is known that the onset of transcription in bovine embryos takes place during stage 3 of nucleologenesis, ie, within the multivacuolated NPB. Our observations indicate that the presence of acidic argyrophilic proteins precedes the onset of transcription, since they are already clearly detected in stages 1 and 2 of nucleologenesis. Similarly, Takeuchi and Takeuchi (1986) also detected silverstained proteins in mouse embryos before the onset of the transcriptional activity. King et al (1989) explained these findings by 3 possible interpretations: 1) preribosomal particles present in the ooplasm associate with the as yet non-functioning nucleolus; 2 ) the silver deposits are associated with a very low level of rRNA gene activity; or 3 ) there is lack of silver-staining specificity.

Since silver staining also takes place in nucleoli without transcriptional activity, it cannot be considered as a general marker of nucleolar activity. Nevertheless, the increasing amount and density of silver deposits (aggregates) within the dense fibrillar component which are involved in ribosomal RNA synthesis and processing suggests some involvement of acidic argyrophilic proteins in the building of the preribosomal RNP machinery.

The specifity of PTA staining has been validated by several authors. Bloom and Aghajanian (1968) demonstated that the treatment of nervous tissues with a $100 \%$ ethanol PTA solution resulted in intense staining of proteins rich in lysine, arginine and histidine. Courtens and Loir (1981) have reported that the PTA method may be specific for lateral lysine residues of proteins in mammalin sperm nuclei.
Takeuchi (1986) showed that in the growing oocytes engaging in active rRNA synthesis, the nucleolar dense fibrillar component and also the fibrillar centers were intensely stained with PTA; the granular component was only slightly stained. In the course of embryonic nucleologenesis we found relatively strong PTA staining in the dense NPB, in the fibrous mass of univacuolar NPB and inside the primary and secondary vacuoles. In the fibrillogranular functional nucleolus, the dense fibrillar component is stained most intensely. Results obtained with PTA staining are very similar to those obtained with silver staining. Both types of proteins are localized in the dense fibrillar component. It is possible that basic PTA-positive proteins which colocalize with the acidic argyrophilic proteins may have a cooperative regulatory function in transcription and ribosome synthesis.

Our study demonstrates that all types of histones tested are present, especially in chromatin structures. However, the initial phases of nucleologenesis (stages 1 and 2) seem to be devoid of histones. In multivacuolated NPBs histones may be present in the nucleolar periphery and in the vacuoles. The presence of histones within the NPBs is probably associated with massive penetration of DNA into the NPBs in this time. Penetration of embryonic DNA into the NPB is the key event of nucleologenesis in early embryo development (Tesarík et al, 1987; Kopećný et al, 1989b).

The low labelling within the NPB in our material is probably a result of the small quantity of histones which may well be below the sensitivity of the peroxidase assay.

Taken together, all these methods provide a clear cytochemical picture of the differentiating nucleolus (fig 13). In brief, acidic argyrophilic proteins accumulate preferentially in the dense fibrillar component, whereas basic protiens and more specifically histones are mostly associated 


\begin{tabular}{|c|c|c|c|}
\hline & $A g+$ proteins & PTA+proteins & histones $\mathrm{H} 2 \mathrm{~B}, \mathrm{HJ}, \mathrm{H} 4$ \\
\hline $\begin{array}{l}\text { nudeolar preaursor } \\
\text { SI body (NPB) }\end{array}$ & What & (4) & $\mathrm{m}^{\prime}$ \\
\hline $\begin{array}{l}\text { NPB with central } \\
\text { S2 vacuole }\end{array}$ & & & \\
\hline $\begin{array}{l}\text { mudeolus with } \\
\text { S3 secondary vacuoles }\end{array}$ & & & \\
\hline $\begin{array}{l}\text { fibrillogranular } \\
\text { nucleolus }\end{array}$ & 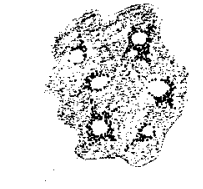 & & \\
\hline
\end{tabular}

Fig 13. Summary of results obtained on the localization of Ag+ proteins, PTA+ proteins and histones in stages S1 to S4. Ag+ proteins are found in a lenticle (S1), within the material of the wall encircling the central vacuole (S2) and in the forming dense fibrillar component (S3 and S4). PTA+ proteins are localized in associated chromatin at all stages and in NPB (S1), in the wall of the vacuoles (S2 and S3), in the vacuoles themselves (patches) and mostly in the dense fibrillar component and the fibrillar centers (S4). Histones are almost entirely restricted to the chromatin at all stages.

with nucleolar chromatin. Our analysis of nucleologeneis will probably be very useful for the evaluation and understanding of changes that occur during nuclear reprogramming, especially following micromanipulation procedures such as nuclear transplantation and the production of cloned embryos.

\section{ACKNOWLEDGMENTS}

The authors wish to express their sincere thanks to JE Fléchon for helpful comments, translation of the French summary and stylistic revision of this manuscript. $S$ Müller is acknowledged for kindly providing the specific antibodies to the histones used in this study. 


\section{REFERENCES}

Altman LG, Schneider BG, Papermaster DS (1984) Rapid embedding of tissues in Lowicryl K4M for immunoelectron microscopy. J Histochem Cytochem 32, 1217-1223

Antalíková L, Fulka J Jr (1990) Ultrastructural localization of silver-staining nuclear proteins at the onset of transcription in early bovine embryo. Mol Reprod Dev 26, 299-307

Bloom FE, Aghajanian GK (1968) Fine structural and cytochemical analysis of the staining of synaptic junctions with phosphotungstic acid. J Ultrastruct Res 22, 361-370

Camous S, Kopečný V, Fléchon JE (1986) Autoradiographic detection of the earliest stage of $\left({ }^{3} \mathrm{H}\right)$-uridine incorporation into the cow embryo. Biol Cell 58, 195-200

Chartrain I, Niar A, King WA, Picard L, St-Pierre $H$ (1987) Development of the nucleolus in early goat embryos. Gamete Res 18, 201-213

Courtens JL, Loir M (1981) Ultrastructural detection of basic nucleoproteins: alcoholic phosphotungstic acid does not bind to arginine residues. J U/trastruct Res 74, 322-326

Fakan S, Hernandez-Verdun D (1986) The nucleolus and the nucleolus organizer regions. Biol Cell 56, 189-206

Fulka J Jr, Motlik J, Fulka J, Jilek F (1986) Effect of cycloheximide on nuclear maturationof pig and mouse oocytes. J Reprod Fertil 77, 281-285

Howell WM, Black DA (1980) Controlled silver staining of nucleolus organizer regions with a protective colloidal developer. A one-step method. Experientia 36, 1014

King WA, Niar A, Chartrain I, Betteridge KJ, Guay $P$ (1988) Nucleolus organizer regions and nucleoli in preattachment bovine embryos. J Reprod Fertil 82, 87-95

King WA, Chartrain I, Kopečný V, Betteridge KJ, Bergeron H (1989) Nucleolus organizer regions and nucleoli in mammalian embryos. $J$ Reprod Fertil 38 (suppl), 63-71

Kopečný V (1989) High-resolution autoradiographic studies of comparative nucleologenesis and genome reactivation during early embryogenesis in pig, man and cattle. Reprod Nutr Dev 28, 589-600
Kopečný V, Fléchon JE, Camous S, Fulka J Jr (1989a) Nucleologeneis in eight-cell bovine embryos. Fine structural autoradiographic study after $(5-3 \mathrm{H})$ uridine incorporation. Mol Reprod Dev 1, 79-90

Kopečný V, Fulka J Jr, Pivko J, Petr J (1989b) Localization of replicated-DNA containing sites in preimplantation bovine embryo in relation to the onset of RNA synthesis. Biol Cell $65,231-238$

Likovsky̌ Z, Smetana K (1981) Further studies on the cytochemistry of the standardized silver staining of interphase nucleoli in smear preparations of Yoshida ascitic sarcoma cells in rat. Histochemistry $72,301-313$

Müller S, Himmelspach K, Van Regenmortel MHV (1982) Immunologial localization of the C-terminal hexapeptide of histone $\mathrm{H} 3$ at the surface of chromatin subunits. EMBO $\mathrm{J} 1$, 421-425

Müller S, Couppes M, Briand JP, Gordon J, Sautiere P, Van Regenmortel MHV (1985) Antigenic structures of histone H2B. Biochim Biophys Acta 827, 235-246

Müller $S$, Isabey $A$, Couppes $M$, Plaue $S$, Sommermeyer G, Van Regenmortel MHV (1987) Specificity of antibodies raised against triacetylated histone $\mathrm{H} 4$. $\mathrm{Mol} / \mathrm{mmol} 24,779$ 789

Sheridan WF, Barrnett JR (1969) Cytochemical studies on chromosome. I Ultrastruct Res 27, 216-229

Takeuchi IK (1986) Ethanol phosphotungstic acid staining of basic proteins in the nucleolar condensation occurring in growing mouse oocytes. J Electron Microsc 35, 173-184

Takeuchi IK, Takeuchi YK (1986) Ultrastructural localization of Ag-NOR proteins in full-grown oocytes and preimplantation embryos of mice. J Electron Microsc 35, 280-287

Telford NA, Watson AJ, Schultz GA (1990) Transition from maternal to embryonic control in early mammalian development: a comparison of several species. Mol Reprod Dev 26 , $90-100$

Tesarík J, Kopečný V, Plachot M, Mandelbaum J, Dalage C, Fléchon JE (1986) Nucleologenesis in the human embryo developing in vitro. Ultrastructural and autoradiographic analysis. Dev Biol 115, 193-203 